\title{
Atrial fibrillation in chronic dialysis patients in the United states: risk factors for hospitalization and mortality Kevin C Abbott*1, Fernando C Trespalacios ${ }^{2}$, Allen J Taylor ${ }^{3}$ and Lawrence Y Agodoa 4
}

Address: ${ }^{1}$ Nephrology Service, Walter Reed Army Medical Center, Washington, D.C., and Uniformed Services University of the Health Sciences, Bethesda, MD, USA, ${ }^{2}$ Nephrology Service, Madigan Army Medical Center, Ft. Lewis, WA, USA, ${ }^{3}$ Cardiology Service, Walter Reed Army Medical Center, Washington, D.C, USA and ${ }^{4}$ NIDDK, NIH, Bethesda, MD, USA

Email: Kevin C Abbott* - kevin.abbott@na.amedd.army.mil; Fernando C Trespalacios - fernando.trespalacios@amedd.army.mil; Allen J Taylor - allen.taylor@na.amedd.army.mil; Lawrence Y Agodoa - agodal@extra.niddk.nih.gov

* Corresponding author

Published: 24 January 2003

BMC Nephrology 2003, 4:1
Received: 23 October 2002

Accepted: 24 January 2003

This article is available from: http://www.biomedcentral.com/l47/-2369/4/I

(C) 2003 Abbott et al; licensee BioMed Central Ltd. This is an Open Access article: verbatim copying and redistribution of this article are permitted in all media for any purpose, provided this notice is preserved along with the article's original URL.

\begin{abstract}
Background: The incidence and risk factors for hospitalized atrial fibrillation have not been previously assessed in a national population of dialysis patients.

Methods: We analyzed the United States Renal Data System (USRDS) Dialysis Morbidity and Mortality Study (DMMS) Wave II in a historical cohort study of hospitalized atrial fibrillation. Data from 3374 patients who started dialysis in 1996 with valid follow-up times were available for analysis, censored at the time of renal transplantation and followed until November 2000. Cox Regression analysis was used to model factors associated with time to first hospitalization for atrial fibrillation (ICD9 code 427.3Ix) adjusted for comorbidities, demographic factors, baseline laboratory values, blood pressures, dialysis modality, and cardioprotective medications.
\end{abstract}

Results: The incidence density of atrial fibrillation was $12.5 / 1000$ person years. Factors associated with atrial fibrillation were older age ( $>=7$ I years vs. $<48$ years), extremes (both high and low) of pre-dialysis systolic blood pressure, dialysis modality (hemodialysis vs. peritoneal dialysis), and digoxin use. Baseline use of coumadin was associated with reduced mortality in patients later hospitalized for atrial fibrillation.

Conclusions: Dialysis patients had a high incidence of atrial fibrillation. This risk was largely segregated among those with established risk factors for atrial fibrillation, and hemodialysis patients. Use of coumadin was associated with improved survival among patients later hospitalized for atrial fibrillation.

\section{Background}

Atrial fibrillation is thought to be more common in chronic dialysis patients than in the general population, although population based comparisons are not available. [1] Atrial fibrillation is worthy of separate study from other dysrythmias due to unique aspects of its natural history and management. [1] Risk factors for atrial fibrillation may be more common in dialysis, and include age, cardiac enlargement and an abnormal calcium-phosphorous metabolism. [2-5] However, the incidence, risk 
Table I: Factors assessed in ESRD patients, DMMS Wave 2, 1996 only

\begin{tabular}{|c|c|c|c|}
\hline Factor & $\mathbf{N}(\%)$ or mean \pm SD & Missing (\%) & $\begin{array}{l}\text { Univariate association with } \\
\text { AFIB }\end{array}$ \\
\hline \multicolumn{4}{|l|}{ Demographic Factors } \\
\hline $\mathrm{N}$ & 3374 & & \\
\hline Female & $1572(46.6)$ & 0 & \\
\hline African American & $933(27.7)$ & 0 & $0.4 I(0.24-0.69)$ \\
\hline Mean Age (Years) & $58.9 \pm 15.9$ & $15(0.4)$ & \\
\hline Quartiles of Age (vs. <48) & 781 & & \\
\hline $48-60$ & 837 & & $3.54(1.17-10.76)$ \\
\hline $6|-7|$ & 867 & & $6.01(2.06-17.52)$ \\
\hline$>71$ & 874 & & $15.26(5.46-42.66)$ \\
\hline \multicolumn{4}{|l|}{ Cardiovascular Factors } \\
\hline History of Coronary Heart Disease & I09I (34.9) & $250(7.4)$ & $2.35(1.60-3.44)$ \\
\hline History of Congestive Heart Failure & $1150(36.2)$ & $199(5.9)$ & $1.80(1.24-2.61)$ \\
\hline Chronic Obstructive Lung Disease & $27 I(8.6)$ & $229(6.8)$ & $1.93(1.13-3.40)$ \\
\hline Stroke & $336(10.5)$ & $164(4.9)$ & $1.69(1.03-2.81)$ \\
\hline Previous CABG & $325(9.6)$ & $118(3.5)$ & $1.87(1.14-3.06)$ \\
\hline Previous PTCA & $174(5.2)$ & $203(6.0)$ & $2.43(1.36-4.35)$ \\
\hline Previous coronary angiography & $352(10.4)$ & $302(9.0)$ & $2.40(1.5 \mathrm{I}-3.8 \mathrm{I})$ \\
\hline $\begin{array}{l}\text { 2nd quartile of pre-dialysis SBP }(130-146 \mathrm{~mm} \mathrm{Hg}) \\
\text { vs. | }{ }^{\text {st }}(<130 \mathrm{~mm} \mathrm{Hg})\end{array}$ & & & $0.49(0.25-0.99)$ \\
\hline \multicolumn{4}{|l|}{ CKD specific factors } \\
\hline Ever Transplanted (Yes/No) & $460(13.6)$ & NA & $0.15(0.05-0.48)$ \\
\hline Peritoneal Dialysis & $1662(49.8)$ & $37(1 . I)$ & $0.59(0.40-0.86)$ \\
\hline \multicolumn{4}{|l|}{ Medications } \\
\hline Aspirin (Yes) & $628(18.6)$ & NA & \\
\hline Coumadin & $198(5.9)$ & NA & \\
\hline Beta-blockers & & NA & \\
\hline Cardioselective & $486(14.4)$ & NA & \\
\hline Non-cardioselective & $177(5.2)$ & NA & \\
\hline Digoxin & $142(4.2)$ & NA & $3.72(2.17-6.38)$ \\
\hline Amiodarone & $19(0.6)$ & NA & \\
\hline Calcium Channel Blockers & & NA & \\
\hline Non-dihyrdopyridine & $439(13.0)$ & NA & \\
\hline Dihydropyridine & $137 \mid(40.6)$ & NA & \\
\hline Statins & $310(9.2)$ & NA & \\
\hline ACE Inhibitors & 772 (22.9) & NA & \\
\hline Levothyroxine & $330(9.8)$ & NA & \\
\hline
\end{tabular}

In column one, data given as the number (\% of total) or mean \pm one standard deviation of patients. Univariate odds ratios (with significance testing by Chi Square) are the strength of the association of a disease or factor with time to hospitalization for atrial fibrillation (AFIB, ICD9 discharge code 427.3I.x), with 1.0 being neutral.

$\mathrm{SBP}=$ systolic blood pressure, $\mathrm{DBP}=$ diastolic blood pressure, both in $\mathrm{mm} / \mathrm{Hg}$, obtained as the mean of three successive blood pressures. $\mathrm{CABG}=$ coronary artery bypass graft, $\mathrm{PTca}=$ percutaneous transluminal coronary angioplasty $\mathrm{LVH}=$ left ventricular hypertrophy, $\mathrm{ECHO}=$ echocardiography, EKG = electrocardiogram. Statin = HMG-CoA reductase inhibitor, NA = not available since variable was constructed from multiple variables ( 15 in the case of medications). Medication use was assessed at day 60 after initiation of dialysis. Comorbidities such as coronary heart disease and congestive heart failure refer to a history of these conditions within ten years prior to the study period. Selective and non-selective beta-blocker use does not total since some patients were on both agents Values for continuous variables more than 3 SD above and below the median were excluded.

factors and associated mortality for hospitalized atrial fibrillation have not been reported for a national population of chronic dialysis patients. Previous studies have also not assessed the effects of cardioprotective medications on atrial fibrillation in dialysis patients. The management of chronic dialysis patients with atrial fibrillation is controversial, since studies of atrial fibrillation have generally excluded patients with chronic renal failure.
$[6,7]$ We therefore performed an historical cohort study of the United States Renal Data System (USRDS) Dialysis Morbidity and Mortality Study (DMMS) Wave 2, which includes information on blood pressure, lipid levels, medications, and other important clinical data. Our objectives were to determine the incidence, and risk factors for hospitalized atrial fibrillation (primary hospitalization discharge ICD9 code 427.31.x), occurring after the initiation 
Table 2: Unadjusted rates of Atrial Fibrillation by high-risk groups

\begin{tabular}{|c|c|}
\hline & Patients in each risk group Hospitalized for atrial fibrillation \\
\hline \multicolumn{2}{|l|}{ Age (Quartiles) } \\
\hline$>=71$ & $76(8.7)$ \\
\hline $61-70$ & $29(3.3)$ \\
\hline $48-60$ & $14(1.7)$ \\
\hline$<=48$ & $4(0.5)$ \\
\hline \multicolumn{2}{|c|}{ Pre-Dialysis SBP, mm Hg (Quartiles) } \\
\hline$<130$ & $40(4.4)$ \\
\hline $130-146$ & $25(3.3)$ \\
\hline $147-162$ & $15(1.9)$ \\
\hline$>162$ & $43(5.0)$ \\
\hline Hemodialysis & $77(4.6)$ \\
\hline Peritoneal Dialysis & $46(2.8)$ \\
\hline \multicolumn{2}{|l|}{ LVH by ECHO } \\
\hline Yes & $20(5.5)$ \\
\hline No & $66(3.6)$ \\
\hline
\end{tabular}

Numbers given in the right column are the $\mathrm{N}(\%)$ of patients in each risk group who were hospitalized for atrial fibrillation during the study period. $\mathrm{SBP}=$ systolic blood pressure, $\mathrm{LVH}=$ left ventricular hypertrophy on echocardiography as specified in the DMMS Wave II facility questionnaire, available at http://www.usrds.org/research.htm

of dialysis but prior to receipt of renal transplantation, as well as determine risk factors for mortality after hospitalized atrial fibrillation.

\section{Methods}

A historical cohort study of the USRDS DMMS Wave 2 was performed. Details on the inception, limitations, validity, variables and questionnaires used in the study are available online at the USRDS researcher's guide website, http:/ /www.usrds.org/research.htm. This database has been used in many previous cross-sectional [8-11] and longitudinal studies, [12-15] including one by our own institution. [16] Briefly, DMMS 2 was a prospective cohort study of a random sample of $20 \%$ of all U.S. hemodialysis patients and virtually all peritoneal dialysis patients starting treatment in 1996 and early 1997. However, because outcomes such as hospitalization and mortality had to be merged with this study from other USRDS files, we did not consider it a true prospective cohort study for the purposes of this analysis. Characteristics of hemodialysis and peritoneal dialysis patients (abstracted from prospective surveys conducted specifically for DMMS 2) were matched and weighted to allow more appropriate comparisons between modalities. Baseline and follow-up data used in the study are shown in Table 1. In addition, a maximum of 15 medications prescribed to each patient at the study start date (day 60 of dialysis) were recorded. From this list, the use of beta-blockers (both cardioselective and non-selective), anti-arrhythmics, coumadin, digoxin, levo-thyroxine, angiotensin-converting enzyme (ACE) inhibitors, calcium channel blockers (subcategorized as dihyropyridine and non-dihydropyridine), 3-hydroxy-3- methylglutaryl coenzyme A (HMG-CoA) reductase inhibitors (statins), and aspirin was determined. For purposes of analysis, cardioselective beta-blockers were atenolol, betaxolol, bisoprolol, metropolol, and acebutolol. Carvedilol was approved for use by the FDA in February 1997, and was therefore not assessed. Blood pressure levels, systolic and diastolic, were obtained as the mean of three readings before and after dialysis, respectively. Pulse pressure, as the difference between systolic and diastolic blood pressure, was also assessed as a covariate in analysis.

Survival status was linked to the DMMS Wave 2 data from the 2000 USRDS Patients Standard Analysis File (SAF.PATIENTS) via unique patient identifiers assigned by the USRDS. The date and cause of death listed in a patient's SAF was obtained from a form submitted to the USRDS by the patient's nephrologist (form HCFA 2746). Patient survival status was complete through 6 November 2000. Hospitalization data was complete through 31 December 1999. Hospitalization data for atrial fibrillation (ICD9 codes 427.31x) were also linked to the DMMS Wave 2 data as above from SAF.HOSP, using only the first hospitalization for a given patient during the study period.

Time to hospitalization for atrial fibrillation was defined as the time from 90 days after the date of the first dialysis session until the first hospitalization for atrial fibrillation, censored for death, receipt of renal transplant, loss to followup or the end of the study period (which was considered 31 Dec 1999 since this was the most recent potential date of hospitalization available in the data files). Survival 


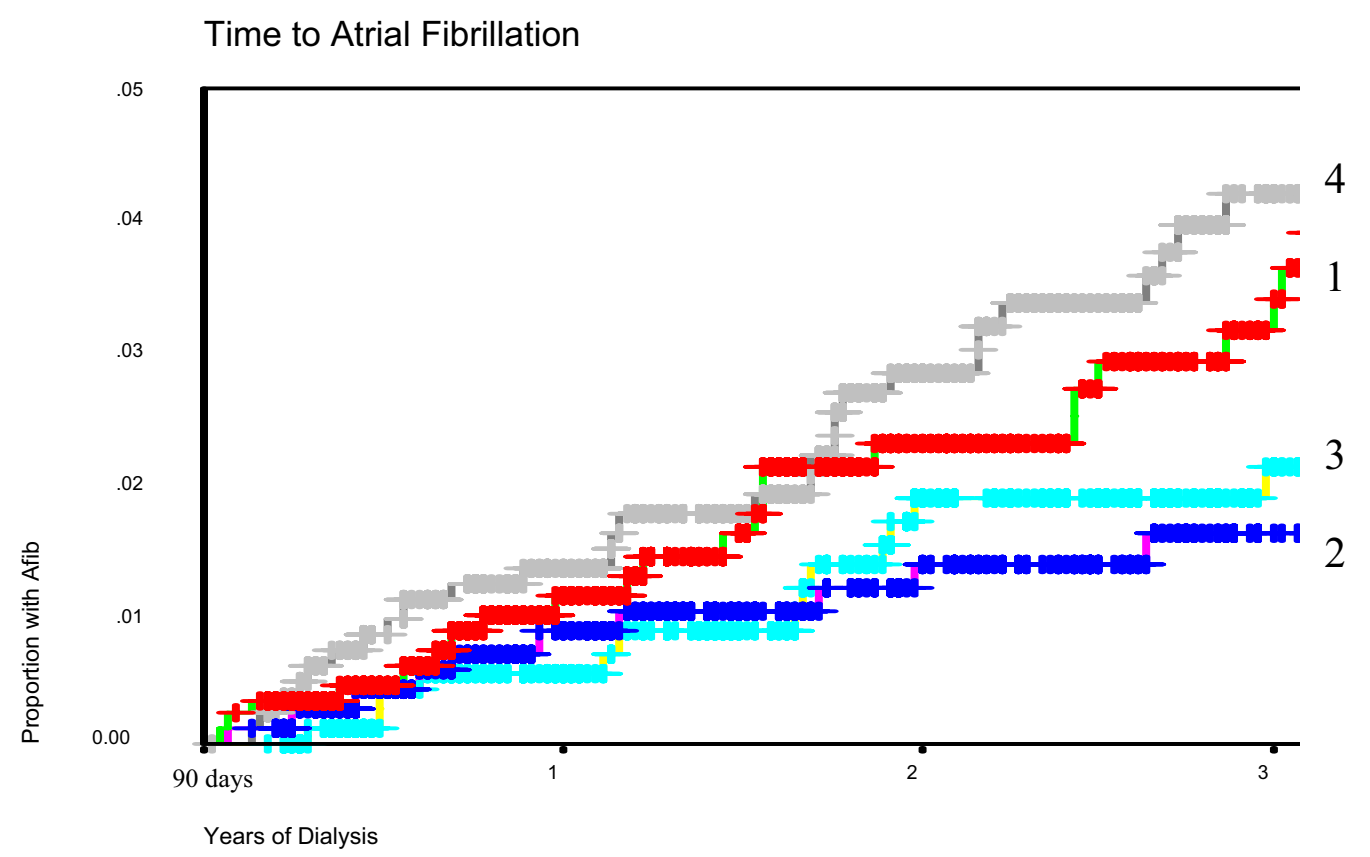

Figure I

Time to Hospitalization for Atrial Fibrillation by Quartile of pre-dialysis systolic blood pressure $(\mathrm{mm} \mathrm{Hg}),(\mathrm{I}=<\mid 30,2=13 \mathrm{I}-$ $146,3=147-162,4=>162$ ). As shown, patients at the extremes of predialysis systolic blood pressure had the greatest risk of subsequent hospitalizations for atrial fibrillation.

time was defined as the time from 90 days after the date of the first dialysis session until the date of death, censored for receipt of renal transplant, loss to followup or the end of the study period (which was considered 6 November 2000 since this was the most recent date of death specified in the data files).

\section{Statistical analysis}

Univariate analysis was performed with Chi-Square testing for categorical variables (Fisher exact test used for violations of Cochran's assumptions) and student's t-test for continuous variables (Mann Whitney test was used for variables without a Gaussian distribution). Variables with borderline significance ( $\mathrm{p}$ value $<0.1$ in univariate analy- sis) and those thought likely to have a clinical relationship with atrial fibrillation, such as cardioprotective medications and blood pressure, were entered into the multivariate models. In addition, variables thought to have a likely clinical relationship with atrial fibrillation were also entered into the multivariate model, in accordance with established epidemiological principles. [17] Stepwise (forward likelihood ratio method) Cox proportional hazards analysis was used to assess the association between baseline factors and hospitalized atrial fibrillation, independent of other factors. Log-log plots were inspected to verify the existence of proportional hazards. Estimated hazard ratios (HR) along with corresponding 95\% confidence intervals (CI) and p values are reported for all re- 
Table 3: Cox Regression Analysis of Factors Associated with Hospitalized Atrial Fibrillation

\begin{tabular}{llll}
\hline & P Value & Hazard Ratio & 95\% Cl \\
\hline Age > = 7I (vs. <48) & 0.0002 & 9.96 & $2.98-33.28$ \\
Hemodialysis (vs. PD) & 0.015 & 2.19 & $1.17-4.13$ \\
Digoxin use (I = present, 0 = absent) & 0.002 & 3.91 & $1.65-9.27$ \\
Pre-Dialysis SBP, mm Hg (vs. <130) & & & $0.15-0.89$ \\
I30-146 & 0.028 & 0.37 & $0.19-0.98$ \\
I47-162 & 0.043 & 0.43 & \\
\hline
\end{tabular}

$\mathrm{SBP}=$ systolic blood pressure, $\mathrm{PD}=$ peritoneal dialysis, $\mathrm{LVH}=$ left ventricular hypertrophy

Table 4: Survival after Hospitalization for Atrial fibrillation

\begin{tabular}{|c|c|c|c|}
\hline & I-year & 2-year & 3-year \\
\hline $\begin{array}{l}\text { Survival after hospitalization for } \\
\text { atrial fibrillation } A\end{array}$ & 75 & 60 & 47 \\
\hline Survival for entire cohort ${ }^{B}$ & 84 & 68 & 55 \\
\hline$P$ value ${ }^{C}$ & $<0.01$ & $<0.01$ & $<0.01$ \\
\hline
\end{tabular}

Survival given in \%. Atrial fibrillation = primary discharge diagnosis ICD9 427.3I, $\mathrm{N}=123$. A Time to hospitalized atrial fibrillation as defined in the methods section. B Survival time as defined in the methods section. CBy univariate Cox non-proportional hazards Regression Test, atrial fibrillation modeled as a time-dependent variable.

gression covariates. Stepwise logistic regression was used to test the independent association of patient factors with preexisting coumadin and cardioselective beta-blocker use, using the same covariates as Cox Regression above. The association of atrial fibrillation with mortality as a time-dependent variable was tested by Cox non-proportional hazards regression analysis as previously described. [18] Hierarchically well-formed models were used in the assessment of interaction terms. [19] Collinearity diagnostics were evaluated both from the output of the statistical procedures and by manual generation of models including only one of several variables with close relationships (for example, congestive heart failure and left ventricular hypertrophy, which was assessed by chest X-ray, electrocardiogram, and echocardiography). Propensity scores $[20,21]$ have been used to adjust for confounding in baseline medication use. Since this method is primarily undertaken to assess uniformity of risk among strata, model fitting was also tested by fitting models to a $70 \%$ random sample of the study population, and then running the same model for the remaining $30 \%$ of the population to test for agreement.

\section{Results}

A total of 4065 patients were included in the DMMS Wave 2 cohort. Of these, 3621 patients had valid dates for starting dialysis in 1996. From this cohort, 3374 had sufficient information to calculate follow-up times. During the time of the study period, 123 patients were hospitalized for a primary discharge diagnosis of atrial fibrillation, with an incidence density of $12.5 / 1000$ person years.

Use of digoxin and particularly levothyroxine was common in dialysis patients. Among other anti-arrhythmic agents, only amiodarone was used by more than $10 \mathrm{pa}-$ tients at baseline, and so is the only other agent reported. Among the study population, cardioselective beta-blockers were used by $14.6 \%$ of patients hospitalized for atrial fibrillation vs. $14.4 \%$ of all other patients; digoxin was used by $12 \%$ of patients hospitalized for atrial fibrillation vs. $3.8 \%$ of all other patients; and coumadin was used by $8.1 \%$ of patients hospitalized for atrial fibrillation vs. $5.6 \%$ of all other patients. Characteristics of the study population, including univariate associations with hospitalized atrial fibrillation, are summarized in Table 1. Table 2 shows the percentage of patients who were hospitalized for atrial fibrillation by risk group. As shown, there were marked disparities by age, blood pressure, dialysis modality, and history of left ventricular hypertrophy.

Table 3 shows significant factors associated with hospitalized atrial fibrillation in multivariate analysis by Cox Regression. Factors positively associated with atrial fibrillation were advanced age ( $>=71$ years vs. age $<48$ years), hemodialysis (vs. peritoneal dialysis), and baseline digoxin use. Pre-dialysis systolic blood pressure had a " $U$ " shaped association with atrial fibrillation, with highest risk associated with the low and high extremes of blood 


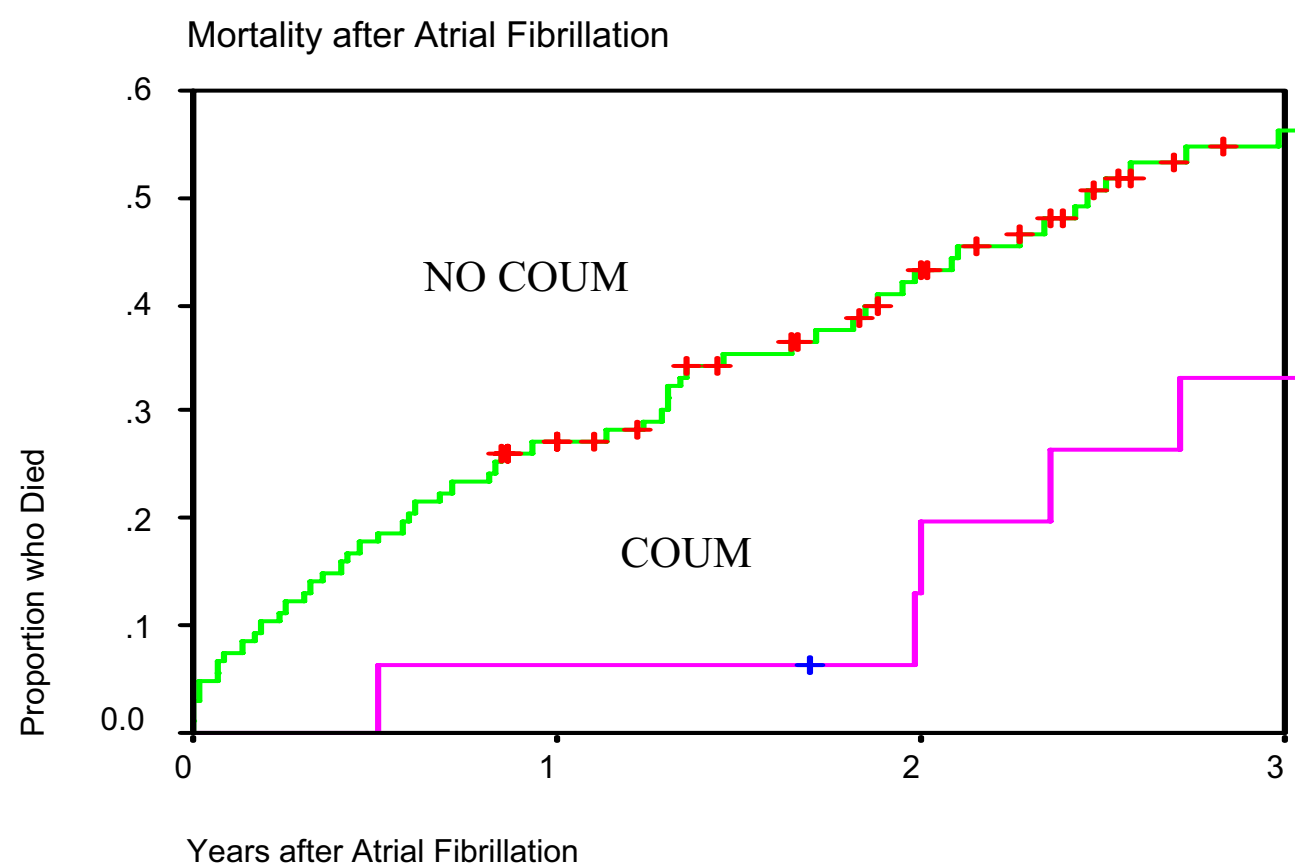

\section{Figure 2}

Mortality after hospitalization for Atrial Fibrillation, limited to patients hospitalized for atrial fibrillation $(M=123)$, stratified by patients with baseline coumadin use (COUM) vs. no baseline coumadin use (NO COUM), $P<0.00$ I by Log Rank Test.

pressure (Figure 1). However, neither pre-dialysis diastolic blood pressure nor post-dialysis blood pressure were associated with the risk of atrial fibrillation, nor were serum albumin levels. No medications except digoxin were independently associated with atrial fibrillation. There were also no significant interactions between terms, specifically between medications, laboratory data or dialysis modality in patients with preexisting coronary heart disease.

There were 1961 total deaths in the cohort through 6 November 2000. Of the 123 patients hospitalized for atrial fibrillation, 90 died during the study period. Mean followup was $2.92 \pm 1.14$ years. Unadjusted survival after atrial fibrillation and for the entire cohort is also shown in Table 4. Survival was significantly worse after atrial fibrillation in Cox non-proportional hazards regression analysis, adjusted hazard ratio for mortality, 1.54, 95\% confidence interval, 1.19-1.99, $\mathrm{p}=0.001$. The leading cause of death among patients hospitalized for atrial fibrillation was unknown $(26 \%)$, followed by cardiac arrest of unknown cause $(19 \%)$, cardiac arrthymia $(8 \%)$, acute myocardial infarction $(7 \%)$, atherosclerotic heart disease $(6 \%)$, cardiomyopathy (3\%) and stroke (3\%). Of patients hospitalized for atrial fibrillation, the most common secondary diagnosis was hypertensive heart disease (15\%), followed by congestive heart failure (11\%). 
Table 5 shows Cox Regression analysis of factors significantly associated with mortality in patients with hospitalized atrial fibrillation. Only two factors, the baseline use of coumadin (Figure 2) and higher systolic blood pressure, were associated with a lower risk of mortality after hospitalization for atrial fibrillation. Of note, calcium channel blockers, specifically non-dihyropyridine calcium channel blockers, were not significantly associated with mortality in patients with atrial fibrillation. In fact, the hazard ratio for mortality of patients with atrial fibrillation using non-dihydropyridine calcium channel blockers was 1.85 , although the $\mathrm{p}$ value was 0.21 and $95 \%$ confidence intervals were 0.69-4.94. Dihydropyridine calcium blockers, as well as ACE inhibitors and aspirin, were also not significantly associated with mortality in patients with atrial fibrillation. Because use of coumadin might be biased by association with factors favorably associated with mortality, logistic regression analysis was performed to assess factors independently associated with use of coumadin. However, only three factors were independently associated with the use of coumadin: left ventricular hypertrophy on echocardiography (adjusted odds ratio, $1.88,95 \% \mathrm{CI}, 1.10-3.20, \mathrm{p}=0.02)$; chronic obstructive lung disease (adjusted odds ratio, 1.98, 95\% CI, 1.053.74); and aspirin use (adjusted odds ratio, 0.31, 95\% CI, $0.14-0.67, \mathrm{p}=0.002$ ). When Cox regression analysis was performed limited to patients who had left ventricular hypertrophy, chronic obstructive lung disease, or did not use aspirin ( $\mathrm{N}$ hospitalized for atrial fibrillation $=87$ ), coumadin use was still significantly associated with improved survival, adjusted hazard ratio, 0.36, 95\% CI, $0.16-0.82, \mathrm{p}=0.014$. Models were robust to testing on random samples of the study population (70\% vs. the remaining 30\%).

\section{Discussion}

In agreement with some previous studies in the general population $[1,4]$ and preliminary reports from the USRDS, [22] atrial fibrillation was associated with increased mortality among chronic dialysis patients. In the general population, cardiovascular events, and not thromboembolic events, are the most common cause of death after atrial fibrillation, [23] in agreement with the findings of the present analysis. However, it is also possible that thromboembolic events could have been underdiagnosed due to a low index of suspicion for thromboembolism in chronic dialysis patients, [24-26] because of the high number of deaths with an unknown cause, the low rate of autopsies in this population, or a combination of these factors. Vazquez et al [5] provide further evidence that causes of death may underestimate the incidence of embolic events in chronic dialysis patients with atrial fibrillation. They reported that $35 \%$ of chronic dialysis patients with atrial fibrillation suffered thromboembolic events at one year of followup.
Risk factors for atrial fibrillation in chronic dialysis patients were consistent with established risk factors $[4,5,27]$, except for the association with hemodialysis (compared with those on peritoneal dialysis). In addition to age, left ventricular hypertrophy is also a well-established risk factor for atrial fibrillation in the general population. Many markers for cardiovascular comorbidity were associated with atrial fibrillation in univariate analysis (Table 1), but not in multivariate analysis (Table 3). While the efficacy of cardioversion in successful conversion of atrial dysrythmias may be helpful in some settings, it is less useful than the duration of the dysrythmia in patients with atrial fibrillation. [28] However, it has never been established whether the same guidelines apply to dialysis patients. The present study could not assess whether cardiac enlargement affected the success rate of cardioversion in dialysis patients hospitalized for atrial fibrillation.

Pre-dialysis systolic blood pressure exhibited a "U" shaped relationship with the risk of atrial fibrillation, which is similar to the "U" shaped relationship of blood pressure with mortality and other cardiovascular events in chronic dialysis patients. Recent reports have indicated that pulse pressure is a more predictive indicator of cardiovascular events in dialysis patients than either systolic or diastolic blood pressure separately. [29] However, pulse pressure was not independently associated with atrial fibrillation in our analysis.

Hemodialysis was associated with a significantly higher risk of atrial fibrillation than peritoneal dialysis in the present study. It is possible this association represents bias, since hemodialysis patients present for medical care much more frequently than peritoneal dialysis patients, and asymptomatic atrial fibrillation is more readily detected. However, there are legitimate reasons why atrial fibrillation might occur more frequently on hemodialysis than on peritoneal dialysis. First, Foley et al demonstrated that progressive cardiac enlargement was more frequent in hemodialysis patients than peritoneal dialysis patients, [2] although these findings were not replicated in a Japanese study. [30] Other investigators have confirmed that LVH progresses despite adequate blood pressure control in hemodialysis patients. [31] Also, hospitalized congestive heart failure is more common in hemodialysis than peritoneal dialysis patients, especially for those on the renal transplant waiting list. [32] The typical regimen for hemodialysis is likely far less physiologic than peritoneal dialysis. Residual renal function may also be preserved longer in patients on peritoneal dialysis, although this is controversial. [33,34] Some or all of these factors may therefore mediate the higher risk of atrial fibrillation associated with hemodialysis. 
Table 5: Cox Regression Analysis of Factors Associated with Mortality in Patients with Hospitalized Atrial Fibrillation

\begin{tabular}{llll}
\hline & P Value & Hazard Ratio & $95 \% \mathbf{C l}$ \\
\hline $\begin{array}{l}\text { Coumadin use Quartiles of Predialysis SBP, } \\
\mathrm{mm} \mathrm{Hg}(\text { vs. }<130)\end{array}$ & 0.014 & 0.39 & $0.18-0.83$ \\
Quartiles of Predialysis SBP, mm Hg (vs. $<130)$ & & & $0.23-0.84$ \\
$\quad 130-146$ & 0.012 & 0.44 & $0.31-0.83$ \\
$>162$ & 0.024 & 0.53 & \\
\hline
\end{tabular}

The effectiveness of coumadin for atrial fibrillation in chronic dialysis patients has not been assessed previously. In fact, previous reports considered chronic renal failure a contraindication to the use of anticoagulation in atrial fibrillation. [35] Wiesholzer et al concluded that non-rheumatic atrial fibrillation was not an independent risk factor for stroke in dialysis patients. [36] Therefore, Figure 2 suggests several possibilities. First, although the clinical indications for coumadin use in this cohort were unknown, coumadin is often given for a limited period of time [31], after which it is often discontinued, in the absence of known predisposing factors. Therefore, patients who were using coumadin at the time of the study assessment and later discontinued it might not have been taking coumadin at the time they were hospitalized for atrial fibrillation, negating a possible beneficial association of coumadin with mortality after hospitalization for atrial fibrillation. Another possibility is that many patients not taking coumadin at baseline may have later been treated with coumadin after hospitalization for atrial fibrillation. Given the growing evidence that dialysis patients in the modern era may actually be hypercoagulable, primarily due to defects of the fibrinolytic system, $[25,37,38]$ clinical trials of the use of anticoagulation in atrial fibrillation and thromboembolic disorders are warranted. Of note, baseline coumadin use, in contrast to digoxin use, was not associated with hospitalization for atrial fibrillation and therefore presumably was not a marker for patients with pre-existing atrial fibrillation.

The decision to use coumadin in patients with atrial fibrillation in whom NSR cannot be established is based on an assessment of both their risk of serious bleeding and their risk of stroke. Coumadin therapy has been associated with improved survival in patients with reduced LV systolic dysfunction in the absence of dysrythmias as well, primarily through reduction in cardiovascular events rather than reduction of thromboembolic events. [39] This may be one explanation for the association of coumadin use with reduced mortality in chronic dialysis patients hospitalized for atrial fibrillation in the present study.

\section{Study limitations}

The present study was observational and not randomized, and therefore associations should not be construed as causative. The study is a random sample of all hemodialysis patients, not the total population, although the peritoneal dialysis population was almost fully captured. We did not have access to information on treatment or conversion to NSR in patients who were hospitalized for atrial fibrillation, nor did we have information on the type of atrial fibrillation for which patients presented and how it was classified within ACC/AHA/ESC guidelines. [40] We did not have access to information on which patients had self-limited episodes of atrial fibrillation vs. those who had persistent atrial fibrillation, nor the duration or presence of atrial fibrillation prior to hospitalization or the study start. We did not have information on left atrial size other than the presence of LVH on echocardiography. We also did not have information on thyroid functions (other than baseline use of thyroxine), alcohol use, or pre-existing atrial dysrythmias. Information bias could have arisen due to mistakes in coding or spelling, especially for medications. We were unable to follow changes in variables over time. Therefore, we could not follow changes in blood pressure, laboratory values, dialysis adequacy, or medications. We could not assess other factors that have shown to be associated with atrial fibrillation, such as hypokalemia or calcified aortic/mitral valves, [41] although there are many similarities between the risk factors for valvular heart disease and atrial fibrillation in chronic dialysis patients. [42] Our use of atrial fibrillation as an outcome variable required survival to reach hospitalization, and thus sudden death was not considered as an outcome. However, causes of death, especially if not verified by autopsy, are also of questionable validity in comparison to the rates of total mortality. [43]

In summary, the present observational, non-randomized study confirms the high incidence and mortality of atrial fibrillation in chronic dialysis patients. Traditional risk factors for atrial fibrillation such, as older age, were confirmed. Hemodialysis, possibly due to a greater frequency of progressive cardiac enlargement or more frequent observation, was also identified as a risk factor for atrial fibrillation. Of the greatest potential importance, the use of 
coumadin at the start of the study was associated with lower mortality in patients later hospitalized for atrial fibrillation. These findings should be confirmed in clinical trials.

\section{Author' contributions}

KCA conceived the original concept, performed the analyses, and wrote most of the manuscript

FCT collaborated in the manuscript and was instrumental in the initial preparation of DMMS 2 files for analysis, especially medications

AJT collaborated in the manuscript providing background on atrial fibrillation and its role in chronic renal failure.

LYA, as Project Director for the NIDDK, is a world expert on the USRDS and was instrumental in the interpretation of USRDS files.

\section{Competing interest}

None declared

\section{References}

I. Zebe H Atrial fibrillation in dialysis patients. Nephrol Dial Transplant 2000, 15:765-8

2. Foley RN, Parfrey PS, Kent GM, Harnett JD, Murray DC and Barre PE Long-term evolution of cardiomyopathy in dialysis patients. Kidney Int 1998, 54:1720-5

3. Ansari N, Manis T and Feinfeld DA Symptomatic atrial arrhythmias in hemodialysis patients. Ren Fail 200I, 23:7I-6

4. Fabbian F, Catalano C, Lambertini D, Tarroni G, Bordin V, Squerzanti R, Gilli P, Di Landro D and Cavagna R Clinical characteristics associated to atrial fibrillation in chronic hemodialysis patients. Clin Nephrol 2000, 54:234-9

5. Vazquez E, Sanchez-Perales C, Borrego F, Garcia-Cortes MJ, Lozano C, Guzman M, Gil JM, Borrego MJ and Perez V Influence of atrial fibrillation on the morbido-mortality of patients on hemodialysis. Am Heart J 2000, I 40:886-90

6. SPAF Investigators The Stroke Prevention in Atrial Fibrillation Study Group Investigators: final results. Circulation |99I, 84:527-39

7. Stroke Prevention in Atrial Fibrillation investigators Adjusted-dose warfarin versus low-intensity, fixed-dose warfarin plus aspirin for high-risk patients with atrial fibrillation: Stroke Prevention in Atrial Fibrillation III randomised clinical trial. Lancet 1996, 348:633-8

8. Stack AG and Bloembergen WE Prevalence and clinical correlates of coronary artery disease among new dialysis patients in the United States: a cross-sectional study. J Am Soc Nephrol 200I, I 2:1516-23

9. Stack AG and Bloembergen WE A cross-sectional study of the prevalence and clinical correlates of congestive heart failure among incident US dialysis patients. Am J Kidney Dis 200I, 38:992-1000

10. Stehman-Breen CO, Gillen D and Gipson D Prescription of hormone replacement therapy in postmenopausal women with renal failure. Kidney Int 1999, 56:2243-7

II. Stehman-Breen CO, Sherrard DJ, Gillen D and Caps M Determinants of type and timing of initial permanent hemodialysis vascular access. Kidney Int 2000, 57:639-45

12. [No authors listed] Medication use among dialysis patients in the DMMS. United States Renal Data System. Dialysis Morbidity and Mortality Study. Am J Kidney Dis 1998, 32(2 Suppl I):S60-8

13. Fung F, Sherrard DJ, Gillen DL, Wong C, Kestenbaum B, Seliger S, Ball $A$ and Stehman-Breen $C$ Increased risk for cardiovascular mor- tality among malnourished end-stage renal disease patients. Am J Kidney Dis 2002, 40:307-14

14. Seliger SL, Weiss NS, Gillen DL, Kestenbaum B, Ball A, Sherrard DJ and Stehman-Breen CO HMG-CoA reductase inhibitors are associated with reduced mortality in ESRD patients. Kidney Int 2002, 61:297-304

15. Kestenbaum B, Gillen DL, Sherrard DJ, Seliger S, Ball A and StehmanBreen C Calcium channel blocker use and mortality among patients with end-stage renal disease. Kidney Int 2002, 6 I:215764

16. Trespalacios FC, Taylor AJ, Agodoa LY and Abbott KC Incident acute coronary syndromes in chronic dialysis patients in the United States. Kidney Int 2002, 62:1799-1805

17. Szklo M and Nieto FJ Epidemiology: Beyond the Basics. Chapter 7, "Stratification and Adjustment: Multivariate Analysis in Epidemiology," page 257. (C) Aspen Publishers, Gaithersburg, MD 2000,

18. Hypolite IO, Bucci J, Hshieh P, Cruess D, Agodoa LY, Yuan CM, Taylor $A J$ and Abbott $K C$ Acute coronary syndromes after renal transplantation in patients with end-stage renal disease resulting from diabetes. Am J Transplant 2002, 2:274-8I

19. David Kleinbaum G Survival Analysis : A Self-Learning Text (Statistics in the Health Sciences) Springer Verlag; New York, New York May 1996

20. Mehta RL, McDonald B, Gabbai F, Pahl M, Farkas A, Pascual MT, Zhuang S, Kaplan RM and Chertow GM Nephrology consultation in acute renal failure: does timing matter? Am J Med 2002 , I | 3:456-6|

21. Stata corporation [http://www.iue.it/Personal//chino/psj7.pdf]

22. Wattigney WA, Mensah GA and Croft JB Increased atrial fibrillation mortality: United States, 1980-1 998. Am J Epidemiol 2002, 155:819-26

23. Casserly LF, Reddy SM and Dember LM Venous thromboembolism in end-stage renal disease. Am J Kidney Dis 2000, 36:405-I I

24. Tveit DP, Hypolite IO, Hshieh P, Cruess D, Agodoa LY, Welch PG and Abbott KC Chronic dialysis patients have high risk for pulmonary embolism. Am J Kidney Dis 2002, 39: I01 I-7

25. Treit DP, Hshieh P, Cruess D, Agodoa LY, Welch PG and Abbott KC Risk factors for pulmonary embolism in chronic dialysis patients. J Nephrol 2002, I 5:24I-7

26. Fumagalli S, Boncinelli L, Bondi E, Caleri V, Gatto S, Di Bari M, Baldereschi G, Valoti P, Masotti $G$ and Marchionni N Does advanced age affect the immediate and long-term results of direct-current external cardioversion of atrial fibrillation? J Am Geriatr Soc 2002, 50: $1192-7$

27. Asinger RW Role of transthoracic echocardiography in atrial fibrillation. Echocardiography 2000, 17:357-64

28. Tozawa M, Iseki K, Iseki $C$ and Takishita S Pulse pressure and risk of total mortality and cardiovascular events in patients on chronic hemodialysis. Kidney Int 2002, 61:717-26

29. Takeda K, Nakamoto M, Baba M, Tanaka T, Yasunaga C, Nishihara G, Matsuo $K$ and Urabe $M$ Echocardiographic evaluation in longterm continuous ambulatory peritoneal dialysis compared with the hemodialysis patients. Clin Nephrol 1998, 49:308-12

30. Covic A, Goldsmith DJ, Georgescu G, Venning MC and Ackrill P Echocardiographic findings in long-term, long-hour hemodialysis patients. Clin Nephrol 1996, 45:104-10

31. Abbott KC, Hypolite IO, Hshieh P, Cruess D, Agodoa LY, Welch PG, Taylor $\mathrm{AJ}$ and Yuan CM The impact of renal transplantation on the incidence of congestive heart failure in patients with endstage renal disease due to diabetes. I Nephrol 200I, I4:369-76

32. Buoncristiani U, Fagugli R, Ciao G, Ciucci A, Carobi C, Quintaliani G and Pasini $P$ Left ventricular hypertrophy in daily dialysis. Miner Electrolyte Metab 1999, 25:90-4

33. Jansen MA, Hart AA, Korevaar JC, Dekker FW, Boeschoten EW and Krediet RT Predictors of the rate of decline of residual renal function in incident dialysis patients. Kidney Int 2002, 62: 10461053

34. Lip GY, Tean KN and Dunn FG Treatment of atrial fibrillation in a district general hospital. Br Heart J 1994, 71:92-5

35. Wiesholzer M, Harm F, Tomasec G, Barbieri G, Putz D and Balcke P Incidence of stroke among chronic hemodialysis patients with nonrheumatic atrial fibrillation. Am J Nephrol 200I, 21:35-9

36. Oda $\mathrm{H}$, Ohno $M$ and Ohashi $\mathrm{H}$ Coagulation and fibrinolysis factors in dialysis patients with and without ischemic heart disease. Adv Perit Dial 2000, 16:152-5 
37. Lottermoser K, Petras S, Poge U, Fimmers R, Hertfelder HJ, Schiermeyer $\mathrm{B}$, Vetter $\mathrm{H}$ and Dusing $\mathrm{R}$ The fibrinolytic system in chronic renal failure. Eur J Med Res 200I, 6:372-6

38. Al-Khadra AS, Salem DN, Rand WM, Udelson JE, Smith JJ and Konstam MA Warfarin anticoagulation and survival: a cohort analysis from the Studies of Left Ventricular Dysfunction. J Am Coll Cardiol 1998, 31:749-53

39. Fuster V, Ryden LE, Asinger RW, Cannom DS, Crijns HJ, Frye RL, Halperin JL, Kay GN, Klein WW, Levy S, McNamara RL, Prystowsky EN, Wann LS, Wyse DG, Gibbons RJ, Antman EM, Alpert JS, Faxon DP, Fuster V, Gregoratos G, Hiratzka LF, Jacobs AK, Russell RO, Smith SC Jr, Klein WW, Alonso-Garcia A, Blomstrom-Lundqvist C, de Backer G, Flather M, Hradec J, Oto A, Parkhomenko A, Silber S and Torbicki A ACC/AHA/ESC Guidelines for the Management of Patients With Atrial Fibrillation: Executive Summary A Report of the American College of Cardiologyl American Heart Association Task Force on Practice Guidelines and the European Society of Cardiology Committee for Practice Guidelines and Policy Conferences (Committee to Develop Guidelines for the Management of Patients With Atrial Fibrillation) Developed in Collaboration With the North American Society of Pacing and Electrophysiology. Circulation 200I, 104(17):2118-50

40. Korzets $A$, Ori $Y$ and Herman $M$ Serum potassium levels and atrial fibrillation in haemodialysis patients. Nephrol Dial Transplant 200I, 16:1090Letter

41. Abbott $K C$ and Agodoa $L Y$ Hospitalizations for valvular heart disease in chronic dialysis patients in the United States. Nephron 2002, 92:43-50

42. Schall LC, Buchanich JM, Marsh GM and Bittner GM Utilizing multiple vital status tracing services optimizes mortality followup in large cohort studies. Ann Epidemiol 200 I, I I:292-296

\section{Pre-publication history}

The pre-publication history for this paper can be accessed here:

http://www.biomedcentral.com/1471-2369/4/1/prepub

\section{Publish with Bio Med Central and every scientist can read your work free of charge}

"BioMed Central will be the most significant development for disseminating the results of biomedical research in our lifetime. "

Sir Paul Nurse, Cancer Research UK

Your research papers will be:

- available free of charge to the entire biomedical community

- peer reviewed and published immediately upon acceptance

- cited in PubMed and archived on PubMed Central

- yours - you keep the copyright 